\title{
A Rare Anatomical Variation in the Pedicle of Anterolateral Thigh (ALT) Flap
}

\author{
Jiten Kumar Mishra ${ }^{1}$ Shamendra Anand Sahu, ${ }^{1, \odot}$ \\ 'Department of Burns and Plastic Surgery, All India Institute of \\ Medical Sciences, Raipur, Chhattisgarh, India
}

\begin{abstract}
Address for correspondence Dr. Jiten Kumar Mishra, MBBS, MS, MCh, Department of Burns \& Plastic Surgery, All India Institute of Medical Sciences, Raipur, Chhattisgarh 492099, India (e-mail: mishra.jitenkumar@gmail.com).
\end{abstract}

\begin{abstract}
Keywords

- anterolateral thigh flap,

- lateral circumflex femoral artery

- anatomical variation of anterolateral thigh flap

Free anterolateral thigh (ALT) flap finds its place in the front row among the soft-tissue flaps used for complex reconstruction of various defects. Its versatile tissue component and ease of harvesting with minimal donor site morbidity made it a popular flap. However, its variable vascular anatomy alerts the reconstructive surgeon to remain aware of the common variation and vigilant with regard to unusual variation. Commonly described variations are about the origin and course of pedicle and perforators. There are rare reports regarding the presence of double arteries and single vein in the flap pedicle. Here, the authors describe these unusual anatomical variations in the pedicle of ALT flap, with two arteries and one vein, and discuss the surgical implication of the same.
\end{abstract}

\section{Introduction}

The anterolateral thigh (ALT) flap is workhorse flap for reconstruction of the soft-tissue defects of head and neck as well as extremity. Due to flexibility in design, like choosing the size of skin paddle, tissue components and less donor site morbidity, the flap offers several advantages over other conventional free flaps. The flap is supplied by the perforators arising from the descending branch of the lateral circumflex femoral artery (LCFA). The descending branch of LCFA, not being a major limb vessel, is expendable. ${ }^{1}$ ALT free flap harvest is often straightforward. With frequent usage of this flap, many anatomical variations are being reported. Normally, the pedicle, the descending branch arising from the LCFA, contains single artery and two venae comitantes. We describe here a rare anatomical variation in the vascular pedicle of the flap, adding to the list of variations which the surgeon may come across during harvest of the flap.

\section{Case Summary}

A 35-year-old male presented with a posttraumatic soft-tissue defect with exposed tendons, tarsal bones on the medial

published online

June 28, 2021
DOI https://doi.org/

10.1055/s-0041-1725226 ISSN 0970-0358. aspect of left side of left foot, and fracture of medial malleolus (-Fig. 1) After fracture fixation with $\mathrm{k}$ wire and debridement, reconstruction was planned with free ALT flap. During ALT flap harvest, musculocutaneous perforators, supplying skin paddle, were located arising from the descending branch. On dissecting the pedicle of the flap proximally, two arteries arising from LCFA and one comitant vein were found (-Fig. 2). The two arteries were separated from the single comitant vein in the pedicle. Both the arteries were pulsating and with flow within (Video 1). The single comitant vein was found in the center with the two arteries along the sides in contrast to the normal anatomical finding in the pedicle, with artery in the center and two venae comitantes along the sides (Video 2). Both the arteries in the pedicle were transected just after their origin from the LCFA. The pedicle length was $7 \mathrm{~cm}$. The comitant vein was $5 \mathrm{~mm}$ in diameter. The artery medial to the comitant vein was $2 \mathrm{~mm}$ in diameter and was a little larger than the artery placed lateral. A flap size of $11 \mathrm{~cm}$ $\times 9 \mathrm{~cm}$ was harvested ( - Fig. 3). Before division of pedicle for selecting the single artery out of the two feeding arteries, we clamped the arteries alternately and observed for flap dermal bleeding, while the flap was being perfused by the other. (c) 2021. Association of Plastic Surgeons of India.

This is an open access article published by Thieme under the terms of the Creative Commons Attribution-NonDerivative-NonCommercial-License, permitting copying and reproduction so long as the original work is given appropriate credit. Contents may not be used for commercial purposes, or adapted, remixed, transformed or built upon. (https://creativecommons.org/licenses/by-nc-nd/4.0/).

Thieme Medical and Scientific Publishers Pvt. Ltd. A-12, 2nd Floor, Sector 2, Noida-201301 UP, India 


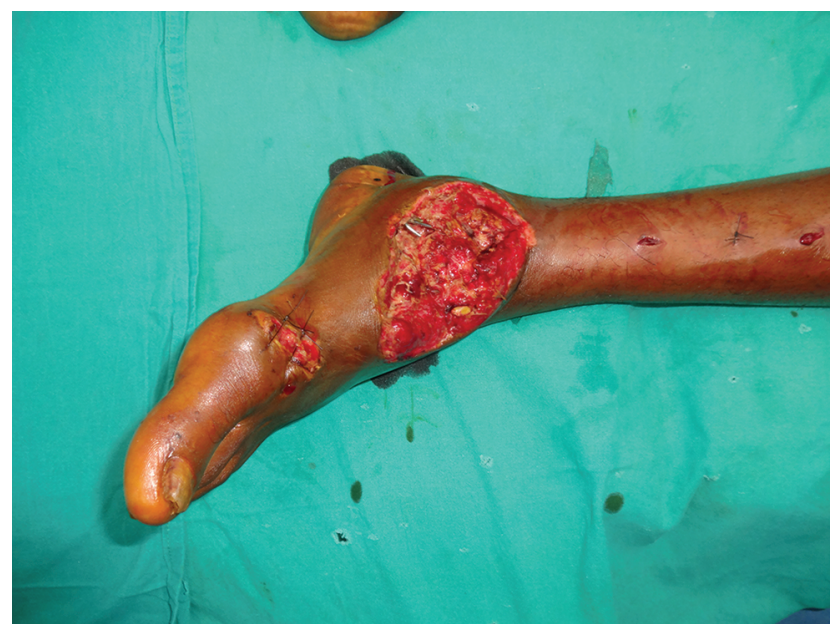

Fig. 1 Soft tissue defect of the left foot.

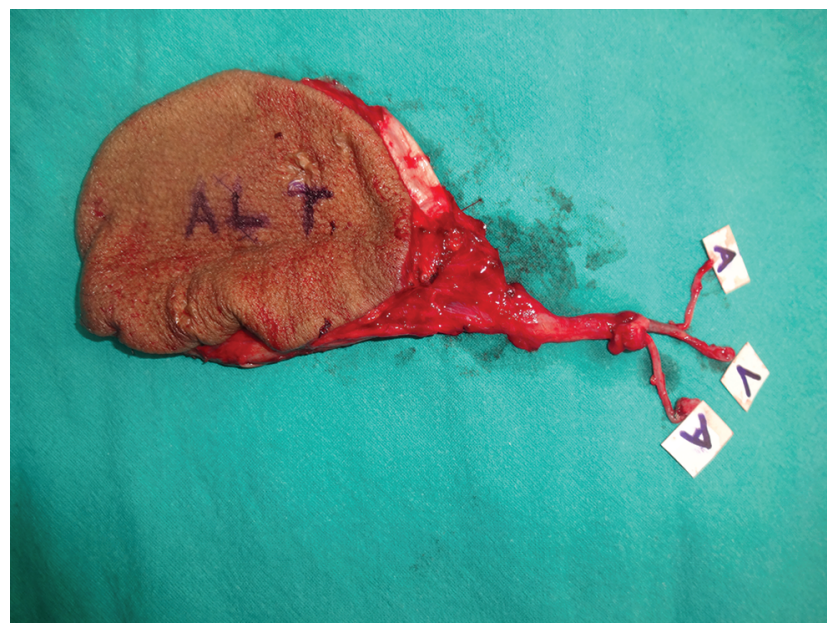

Fig. 3 Harvested anterolateral thigh (ALT) flap with two arteries and single vein.

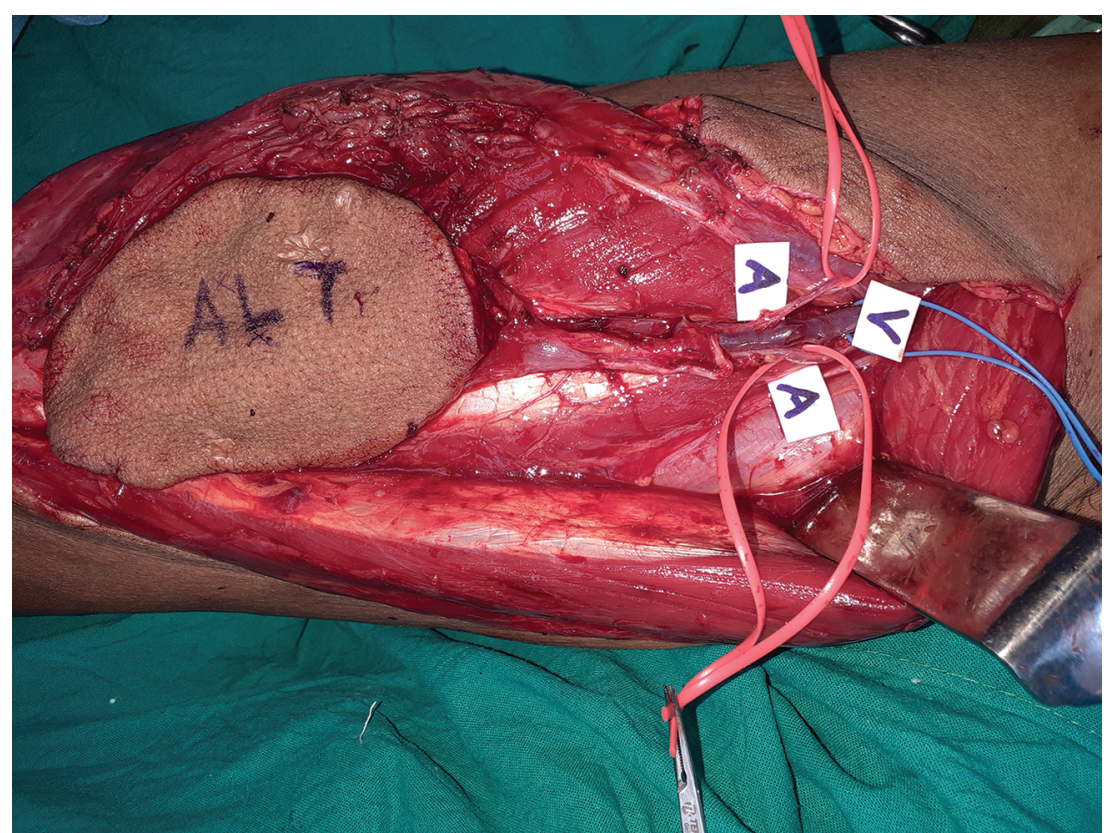

Fig. 2 Anterolateral thigh (ALT) flap in situ with pedicle showing two arteries alongside a single vein in the center.

\section{Video 1}

Intraop video showing pulsation of both arteries in the pedicle of anterolateral thigh (ALT) flap. Online content including video sequences viewable at: https:// www.thieme-connect.com/products/ejournals/ $10.1055 / \mathrm{s}-0041-1725226$.

\section{Video 2}

Intraop video showing both arteries and single central comitant vein labeled. Online content including video sequences viewable at: https://www.thieme-connect. com/products/ejournals/ 10.1055/s-0041-1725226.
The artery with a little large caliber was found with better dermal bleeding; thus, marked and chosen for anastomosis. End-to-end arterial anastomosis was established with anterior tibial artery. Since the single vein in the pedicle was of $5 \mathrm{~mm}$ in diameter and the venae comitantes of anterior tibial artery were $2 \mathrm{~mm}$ and $1.5 \mathrm{~mm}$. respectively, to avoid caliber mismatch, great saphenous vein was chosen as recipient vein. Flow was established intraoperatively and there was no vascular compromise postoperatively ( - Fig. 4).

\section{Discussion}

In spite of so many advantages of ALT flap, the main disadvantage which concerns the surgeon during flap harvest is vascular anatomical variability., ${ }^{2,3}$ The main pedicle of the ALT flap commonly arises from the LCFA and contains a single artery and two venae comitantes. A case of ALT flap, whose 


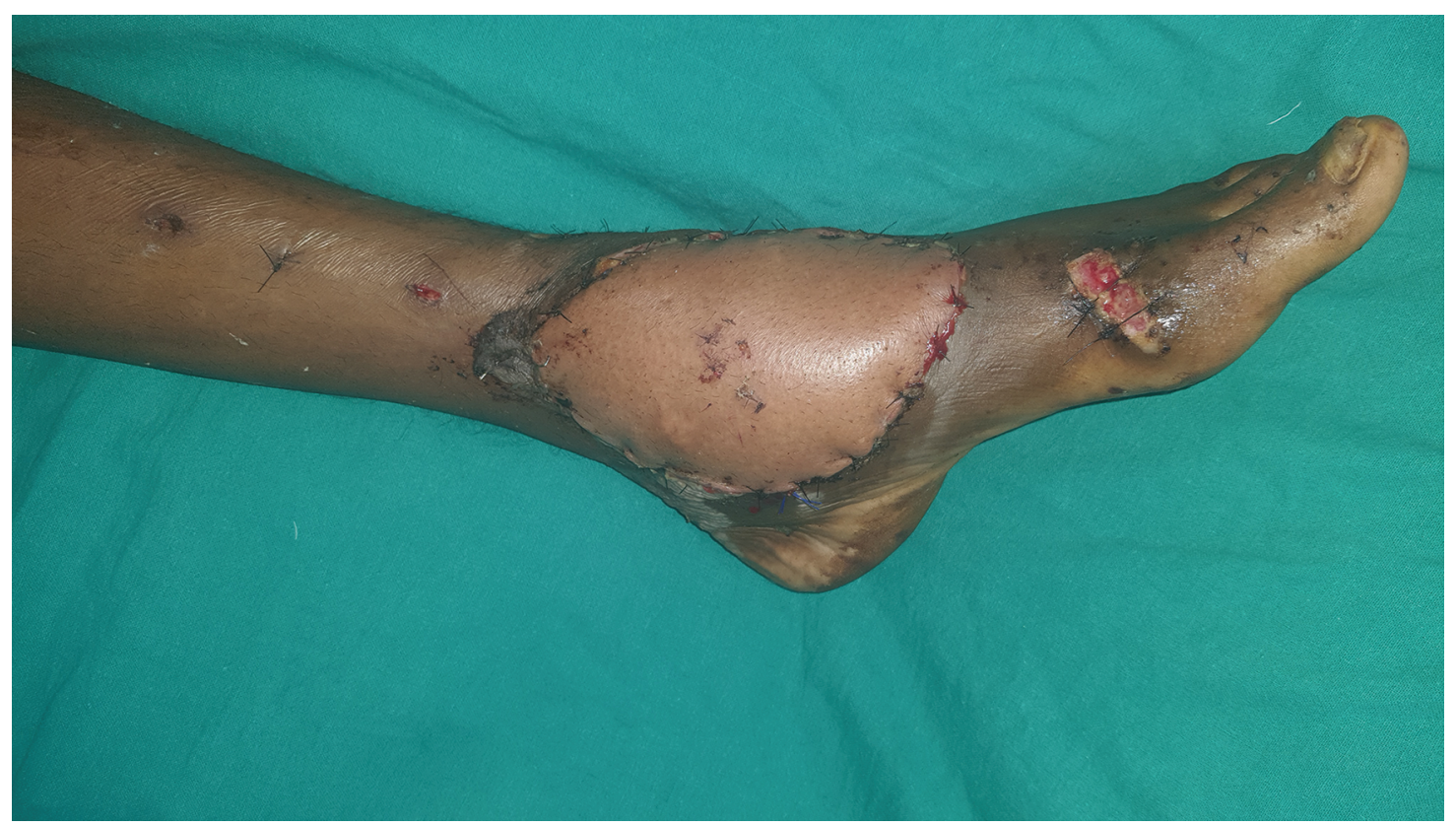

Fig. 4 Postop picture showing well-settled flap.

arterial pedicle was directly a branch of the femoral artery, has also been described. ${ }^{4}$ Bhujel et al reported duplication of the descending branch of lateral circumflex femoral artery in ALT flap pedicle. In their case, the flap pedicle was having two arteries with two normal venae comitantes. ${ }^{5}$ Our case was having variation in arterial component with double arteries as well as in the venous anatomy with a single comitant vein; thus, different from the case reported by Bhujel et al.

In our case, for better flap vascular hemodynamics, the artery with superior flap perfusion was chosen by occluding either arteries and observing the dermal bleeding with the flap in situ. Due to single large comitant vein in the pedicle, selection of recipient vein was important. For appropriate caliber match and venous drainage, end-to-end anastomosis of the only comitant vein of the flap with great saphenous vein was done rather than vena comitant of the anterior tibial artery.

Alternatively, in such cases, double arterial anastomosis can be established by side-to-side anastomosis of the two arteries in the flap pedicle to anterior tibial artery, or end-to-end anastomosis of one flap artery to proximal end of anterior tibial artery, and the other flap artery to distal end of anterior tibial artery, in view of patent plantar arch. Finally, the disposition of vein and artery in flap pedicle in this kind of variation, as in ours, alerts the surgeon to avoid inadvertent anastomosis of the flap donor vein with the recipient artery.

\section{Conclusion}

Presence of double artery and single vein in the pedicle of ALT flap is a rare anatomical variation. During ALT flap harvesting and reconstruction, the surgeon has to be prepared for the possibility of anatomical variations and should have another plan ready if such an eventuality arises.

\section{Conflicts of Interest}

None declared.

\section{References}

1 Koshima I, Fukuda H, Utunomiya R, Soeda S. The anterolateral thigh flap; variations in its vascular pedicle. Br J Plast Surg 1989;42(3):260-262

2 Gedebou TM, Wei FC, Lin CH. Clinical experience of 1284 free anterolateral thigh flaps. Handchir Mikrochir Plast Chir 2002;34(4):239-244

3 Yu P. Characteristics of the anterolateral thigh flap in a Western population and its application in head and neck reconstruction. Head Neck 2004;26(9):759-769

4 Sagheer SH, Reschly W. A case report of aberrant vascular anatomy of the anterolateral thigh flap. Cureus 2019;11(12):e6385

5 Bhujel N, Johnston C, Parmar S, Martin T. An unusual anatomical variant of the vascular anatomy in the anterolateral thigh free flap. Int J Oral Maxillofac Surg 2010;39(1):94-95 